\title{
Spatiotemporal Distribution of Precipitation Recycling across the Arid Regions of Asia and Africa
}

\author{
Jiamin Li, Ruirui Si \\ Key Laboratory of Arid Climate Change and Disaster Reduction of Gansu Province, College of Atmospheric Sciences, Lanzhou \\ University, Lanzhou, China \\ Email: jmli2012@lzu.edu.cn
}

How to cite this paper: Li, J.M. and $\mathrm{Si}$, R.R. (2018) Spatiotemporal Distribution of Precipitation Recycling across the Arid Regions of Asia and Africa. Journal of Geoscience and Environment Protection, 6, 195-206.

https://doi.org/10.4236/gep.2018.69015

Received: August 24, 2018

Accepted: September 25, 2018

Published: September 28, 2018

Copyright $\odot 2018$ by authors and Scientific Research Publishing Inc. This work is licensed under the Creative Commons Attribution International License (CC BY 4.0). http://creativecommons.org/licenses/by/4.0/

\begin{abstract}
The degree of water vapour recycling in terrestrial precipitation is still a debatable topic, particularly in arid regions. Here, the spatiotemporal evolution of evaporation, calculated via the water balance method [1], and the precipitation recycling ratio, calculated using a water recycling model [2], are investigated across Asia and Africa for the 1984-2013 time period. The results show that the precipitation recycling ratio in North Africa and China-Mongolia is stronger in summer but weaker in winter. However, it is stronger in winter and spring in West Asia but weaker in summer. Evaporation accounts for a small proportion of the precipitation uptake in arid regions, with external water vapour transportation exerting the primary influence on precipitation recycling. Increasing global temperatures and evaporation potentials over the past 30 years have driven the actual evaporation and precipitation recycling ratio increases in North Africa and West Asia and corresponding decreases in China-Mongolia.
\end{abstract}

\section{Keywords}

Evaporation, Precipitation Recycling, Arid Regions

\section{Introduction}

The precipitation forming mechanism in arid regions continues to be a debated topic. There are two key water vapour components that lead to precipitation, local evaporation and external water vapour transportation [3]. The total oceanic water vapour evaporationis $4.2 \times 10^{5} \mathrm{~km}^{3} \cdot \mathrm{a}^{-1}$, but only $3.9 \times 10^{4} \mathrm{~km}^{3} \cdot \mathrm{a}^{-1}$ is transported to land, whereas terrestrial evaporation accounts for $8.1 \times 10^{4} \mathrm{~km}^{3} \cdot \mathrm{a}^{-1}$, 
which is twice the amount of oceanic water vapour transportation [4] [5]. It is therefore important to constrain the proportion of terrestrial evaporative vapour in precipitation. This is described using precipitation recycling, the contribution of local evaporation to precipitation in a given area [6], which is one of the most important indicators for measuring the extent of land-to-atmosphere effects. The greater the precipitation recycling, the smaller the net income of surface water vapour in the area, which yields a much stronger land-atmosphere interaction.

Studies have shown that the proportion of water vapour in the atmosphere accounts for only $1.53 \%$ of the total global water-cycle. There are limited water vapour sources in arid regions, with surface hydrological processes playing a major role in the regional water balance [7] [8]. The complex precipitation recycling process can be simplified via numerical modelling, which simulates the primary features. There have been many comprehensive studies that employed the precipitation recycling model [3]. Bulk recycling models have recently received more much attention because many hypotheses have been released [9].

This paper mainly studies the characteristics of hydrological cycle in arid regions where water resources are scarce. The proportion of local evaporation in precipitation is paid more attention by using the Dynamic Recycling Model (DRM) [2] which is a Lagrangian moisture recycling model. On this basis, due to the impact of global warming, how the precipitation recycling ratio changes in the regions is also considered.

This paper is organized as follows. Section 2 describes the data used, the domain studied and the method for estimating evaporation and the precipitation recycling model. The analysis and results are provided in Section 3. Finally, the discussion and conclusions are given in Section 4.

\section{Data, Research Area and Methodology}

\subsection{Data}

The specific humidity and horizontal $(\mathrm{u}, \mathrm{v})$ components of the wind data were obtained from the data product of the European Centre for Medium-Range Weather Forecasts (ERA-Interim), with a resolution of $1.5^{\circ} \times 1.5^{\circ}$ from 1984 to 2013. But the precipitation data of ERA-Interim is the precipitation forecast. Here monthly global precipitation data from 1984 to 2013, with a resolution of $0.5^{\circ} \times 0.5^{\circ}$, were obtained from the Global Precipitation Climatology Centre which analyzed in many researches and the accuracy was demonstrated [10] [11] [12] [13]. It is reasonable for using this precipitation data.The data with a resolution of $1.5^{\circ} \times 1.5^{\circ}$ changed into $0.5^{\circ} \times 0.5^{\circ}$ by grid difference method. In the large scale of this paper, the results would not be impacted.

\subsection{Research Areas}

Arid regions are commonly defined as receiving less than $200 \mathrm{~mm}$ annual precipitation [14] [15]. The arid regions of Asia and Africa defined in this paper are 
the same as in Thomas [14], and are identified in Figure 1. Drought, one of the major calamitous climate disasters, is generally driven by one of two primary aspects in arid regions, the sinking of tropical Hadley circulation or topography [1]. The three studied arid regions are representative of these two typical types of arid regions. North Africa and West Asia appear to be primarily influenced by the sinking movement of the radial Hadley circulation in subtropical areas, whereas the topography of China-Mongolia makes it difficult to transport large amounts of water vapour due to the long distance from the ocean and the large orography of the region.

\subsection{Methods}

Here evaporation is computed from the water mass balance with atmospheric moisture changes neglected [1]. For the multi-year average water balance, its factors use the average value for many years. During a long period of time, the change in water vapor in the atmosphere tends to be balanced. And the water balance equation can be simplified [16] [17]:

$$
E \approx P+\nabla Q
$$

where $E\left(\mathrm{~mm} \cdot \mathrm{d}^{-1}\right)$ is evaporation, $P\left(\mathrm{~mm} \cdot \mathrm{d}^{-1}\right)$ is precipitation, $\nabla Q\left(\mathrm{~mm} \cdot \mathrm{d}^{-1}\right)$ is the divergence term of the moisture flux and $Q\left(\mathrm{~kg} \cdot \mathrm{m}^{-1} \cdot \mathrm{s}^{-1}\right)$ is the precipitable water, which is the vertically integrated water vapour flux. This method is one of the simplest methods to calculate evaporation, and many previous studies have shown that the monthly estimates from this scheme are reliable over long timescales [18].

The water vapour source in the air above an area consists of two components, local evaporation and water vapour that has been transported into the area from the land and ocean surfaces. The precipitation recycling in a region is the ratio of precipitation with an evaporation source to total precipitation, which indicates the proportion of local water circulation in total precipitation. Here the DRM [2]

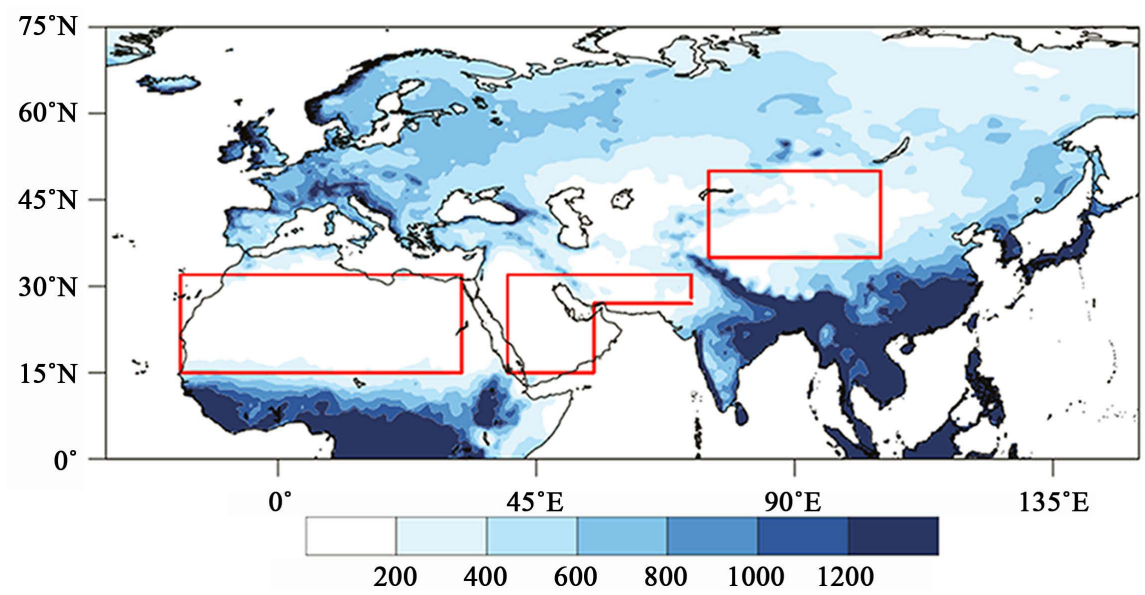

Figure 1. Annual precipitation ( $\mathrm{mm}$ ) distribution across Asia and Africa, with the main arid regions (red boxes, the left box for North Africa, the middle box for West Asia, and the right box for China-Mongolia) calculated for the 1984-2013 time period. 
is used to calculate the precipitation recycling rate. The DRM is a Lagrangian moisture recycling model, which is based on the atmospheric moisture balance equation. This model is first established in the Lagrangian coordinate system $(\chi, \xi, \tau)$ as

$$
\begin{aligned}
& \chi=x-u t \\
& \xi=y-v t \\
& t=\tau
\end{aligned}
$$

where $x$ and $y$ are the horizontal Cartesian coordinates, and $t$ is the time. The evaporation $E$, precipitation recycling ratio $\rho\left(\mathrm{mm} \cdot \mathrm{mm}^{-1}\right)$ and precipitable water $Q$ are then converted to the Lagrangian coordinate system as follows:

$$
\begin{aligned}
& E(x, y, t)-\varepsilon(\chi, \xi, \tau) \\
& \rho(x, y, t)-R(\chi, \xi, \tau) \\
& Q(x, y, t)-\omega(\chi, \xi, \tau)
\end{aligned}
$$

where $\varepsilon\left(\mathrm{mm} \cdot \mathrm{d}^{-1}\right), R\left(\mathrm{~mm} \cdot \mathrm{mm}^{-1}\right)$ and $\omega\left(\mathrm{kg} \cdot \mathrm{m}^{-1} \cdot \mathrm{s}^{-1}\right)$ are the evaporation, precipitation recycling ratio and precipitable water in the Lagrangian coordinate system, respectively.

The assumption of a well-mixed atmosphere allows the precipitation recycling ratio to be rewritten as

$$
\operatorname{PRR}(\chi, \xi, \tau)=1-\exp \left[-\int_{0}^{\tau} \frac{\varepsilon(\chi, \xi, \tau)}{\omega(\chi, \xi, \tau)} \partial \tau^{\prime}\right]
$$

\section{Result and Analysis}

Evaporation rates of less than $3 \mathrm{~mm} \cdot \mathrm{d}^{-1}$ are observed at high latitudes $\left(45^{\circ}\right.$ $\left.75^{\circ} \mathrm{N}\right)$, with rates of higher than $4 \mathrm{~mm} \cdot \mathrm{d}^{-1}$ observed at mid-low latitudes $\left(0^{\circ}\right.$ $45^{\circ} \mathrm{N}$ ) (Figure 2(a)). The minimum evaporation across the three studied arid regions studied is less than $0.5 \mathrm{~mm} \cdot \mathrm{d}^{-1}$. Seasonal variations in the evaporation rate are much stronger in summer and weaker in winter across much of the Northern Hemisphere. For example, the evaporation rate in China-Mongolia and North Africa is around $0.8 \mathrm{~mm} \cdot \mathrm{d}^{-1}$ in summer, decreasing to less than 0.5 $\mathrm{mm} \cdot \mathrm{d}^{-1}$ in the winter. However, the evaporation rate in West Asia is stronger in winter, at around $1.2 \mathrm{~mm} \cdot \mathrm{d}^{-1}$, and weaker than $0.4 \mathrm{~mm} \cdot \mathrm{d}^{-1}$ in summer. West Asia is affected by the Mediterranean climate, with more precipitation in winter and spring, whereas North Africa and China-Mongolia are affected by the monsoon climate, with more precipitation in summer. Evaporation in arid regions is always the minimum in the North Hemisphere and the seasonal evaporation characteristics yield trends that are similar to the precipitation patterns in arid regions. This highlights that evaporation in arid regions is primarily limited by the lack of water vapour, with the arid regions possessing the minimum evaporation values throughout the year.

Precipitation recycling is a robust component of precipitation formation, particularly in terrestrial precipitation, which has strong regional characteristics 

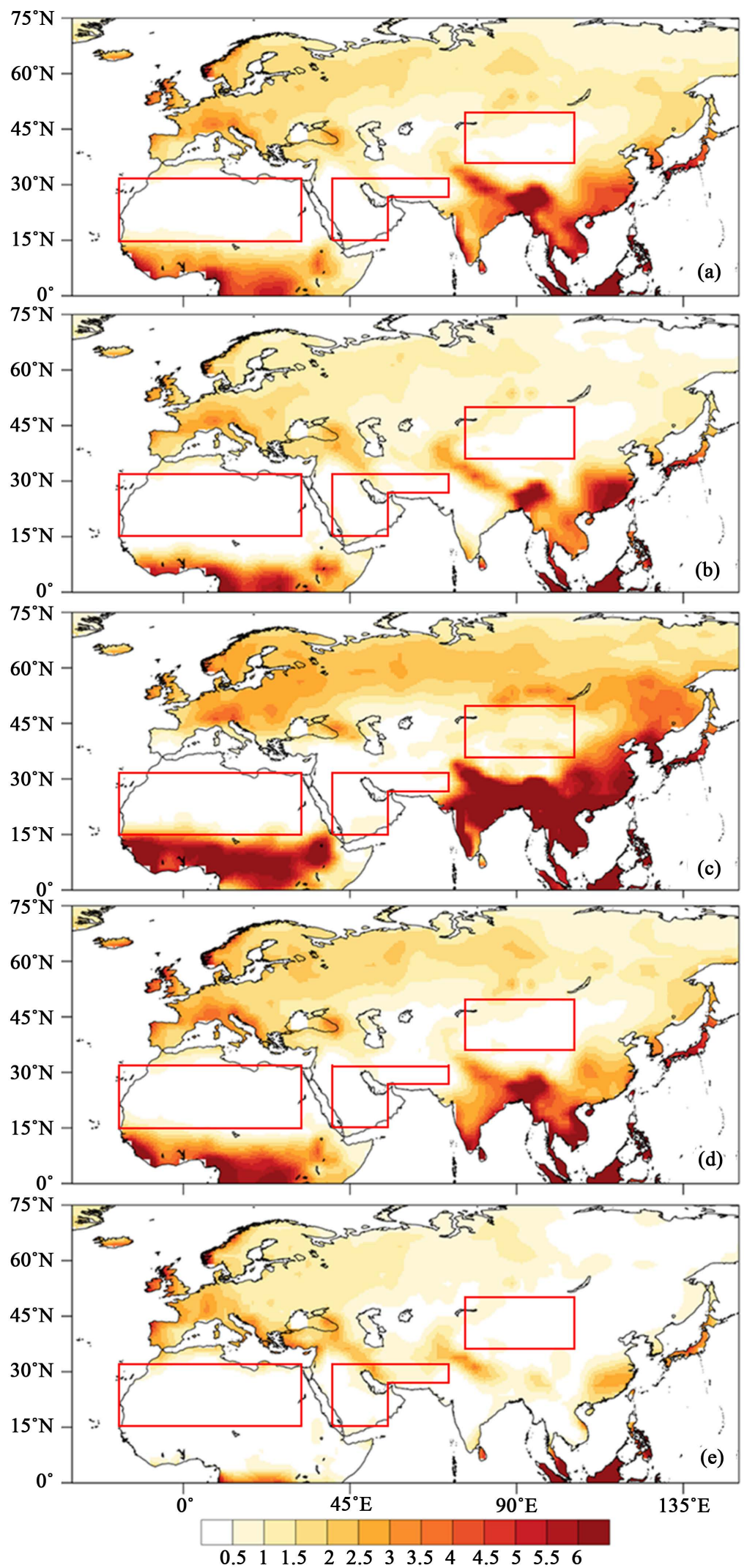

Figure 2. Evaporation $\left(\mathrm{E}, \mathrm{mm} \cdot \mathrm{d}^{-1}\right.$ ) distribution, calculated for the 1984-2013 time period. (a) Annual; (b) Spring; (c) Summer; (d) Autumn; (e) Winter. 
that are dependent on the terrestrial evaporation trends. External vapour transportation is deficient in arid regions, making precipitation recycling more crucial in precipitation. Figure 3 shows the precipitation recycling rate, with evaporation calculated via the water mass balance method. The annual average precipitation recycling rate is stronger at high latitudes $\left(45^{\circ} \mathrm{N}-75^{\circ} \mathrm{N}\right)$, yielding values of more than $0.1 \mathrm{~mm} / \mathrm{mm}$ (Figure 3(a)), whereas the arid regions possess minimum values of less than $0.04 \mathrm{~mm} / \mathrm{mm}$. This highlights lower precipitation recycling in these arid regions than in other regions, whereas the precipitation from advective water vapour water is more important in these regions. Note that the precipitation recycling rate exhibits obvious seasonal variations. The high-latitude precipitation recycling rate is more than 0.14 in spring, yielding higher values over Asia and Africa (Figure 3(b)). It then decreases at high latitudes in summer but increases in the tropic and subtropic regions around the equator (Figure $3(\mathrm{c})$ ). The high-latitude precipitation recycling rate during autumn and winter increases to 0.2 but drops below 0.02 around the equator (Figure 3(d) and Figure 3(e)). The precipitation recycling rate trends yield different seasonal variations between the three arid regions. The precipitation recycling rate in West Asiais stronger in winter and spring but lower in summer. However, it is stronger in summer and lower in winter in China-Mongolia and North Africa. The seasonal precipitation recycling rate variations are similar to the seasonal evaporation variations in arid regions. This suggests that the proportion of the local water cycle that contributes to total precipitation depends on a suitable evaporation estimation in arid regions since water vapour sources are scarce.

The precipitation recycling rate calculated by $\mathrm{Li}$ [19] shows that the arid regions are not the minimum precipitation recycling ratio centres since they possess much larger values than other regions. However, the results of Trenberth [5] and Ent, Savenije [20] show that the annual precipitation recycling ratio in North Africa, West Asia and China-Mongolia is less than 0.03, which is similar to our results. Differences arise at the high latitudes, though, with a much stronger precipitation recycling ratio estimated here. Dirmeyer et al. [21] showed that the precipitation recycling ratio is higher at high latitudes, with different evaporation patterns being the primary reason. The evaporation limited by the water supply is much smaller than that by Penman evaporation, such that the proportion of precipitation due to evaporation relative to the total precipitation would be small.

The precipitation recycling ratio in the three arid regions has similar characteristics. Compared with it in the surrounding areas, arid regions are always the small value regions. Evaporation has little effect on precipitation in the three arid regions. The minimum precipitation recycling ratio is observed in the arid regions, and the evaporation vapour contribution to precipitation is smaller in the arid regions than in the other regions. This means that precipitation in arid regions is heavily dependent on water vapour transportation, with evaporation 

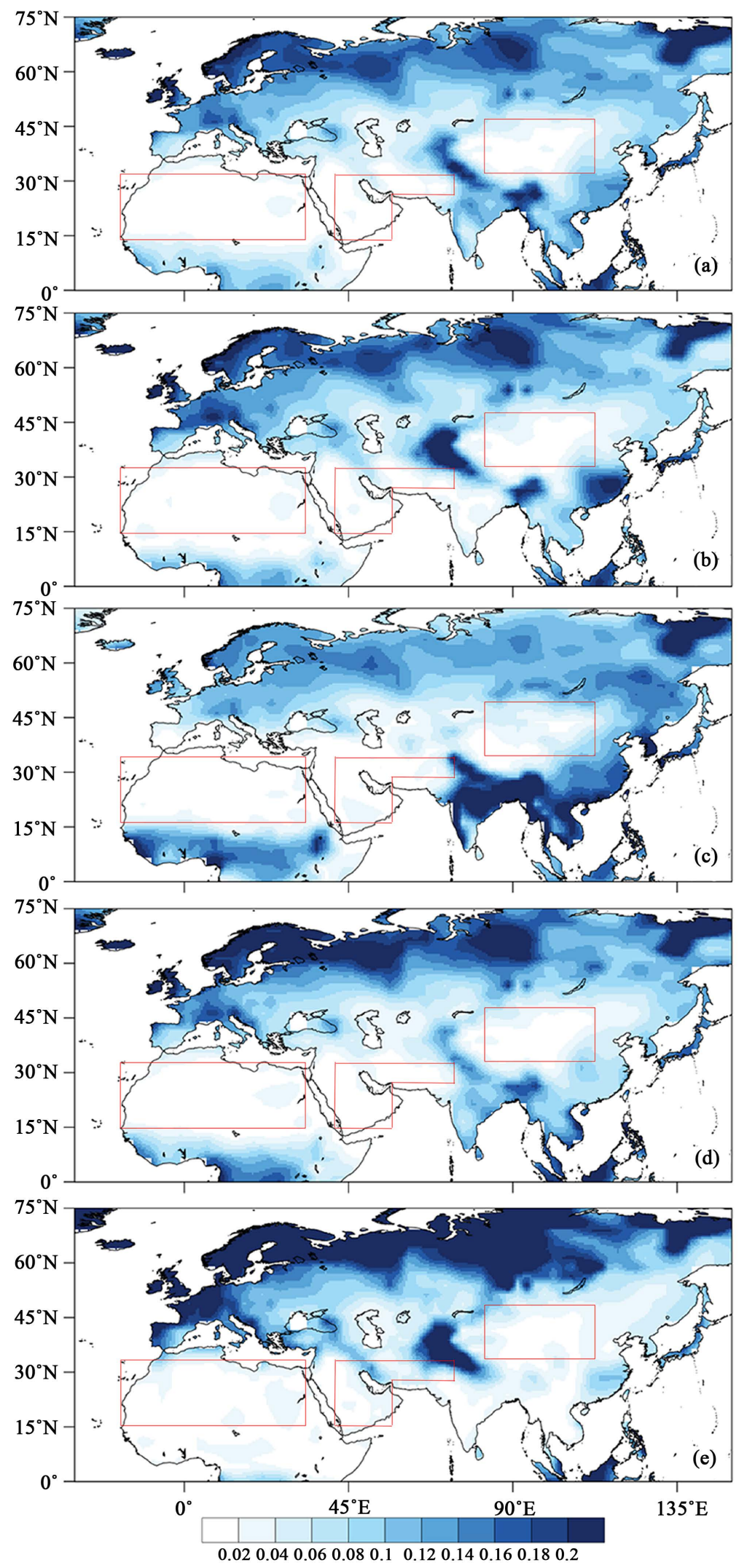

Figure 3. Precipitation recycling ratio $\left(\mathrm{PRR}, \mathrm{mm} \cdot \mathrm{mm}^{-1}\right.$ ) distribution, calculated for the 1984-2013 time period. (a) Annual; (b) Spring; (c) Summer; (d) Autumn; (e) Winter. 
contributing less to precipitation. Water vapour transportation is an important part of the global water cycle and plays an important role in regional water balances. It is therefore necessary to understand the water circulation transport function to fully explain how water recycling can be sustained.

Figure 4 shows the average water vapour transport flux and its divergence from 1984 to 2013. Water vapour transportation via the west wind belt plays an important role in the annual moisture supply to the three arid regions (Figure 4(a)). The moisture entering North Africa is mainly supplied via the West Atlantic inflow, and the main sources of water vapour in West Asia are the Red Sea and Mediterranean Sea. However, the main water vapour sources for ChinaMongolia are land based. The corresponding water vapour flux divergence field shows that the water vapour transportation over China-Mongolia and West Asia is mainly manifested as water vapour convergence. However, convergence and divergence zones lie to the west and east of North Africa, respectively. Water vapour flux is stronger in China-Mongolia in summer (Figure 4(c)) and weaker in winter (Figure 4(e)), whereas it is stronger in West Asia from winter to spring and weaker in summer. The summer moisture in North Africa is sourced from the northeast (Figure 4(c)). The water vapor sources of precipitation in arid regions are mainly upwind regions. However, something different with the sources for arid regions, the area of water vapor that affects North Africa and West Asia is the surface of the ocean, but the area that affects China-Mongolia is the land. This can be indirectly explained, the formation reason of the three arid regions is different.

There has been a significant increase in global temperatures over the past 30 years, particularly in the arid regions of the Northern Hemisphere [22]. However, the effect of this increase in temperature on evaporation and the precipitation recycling ratio in arid regions is still debated. Figure 5 indicates that the arid regions have undergone minimal changes in evaporation and the precipitation recycling ratio during the 1984-2013 time period. Li [19] results revealed that Penman evaporation increases in these arid regions with increasing temperature. However, the actual evaporation decreases in North Africa and West Asia, and the annual evaporation gradient is 0.11 and $2.23 \mathrm{~mm} \cdot \mathrm{a}^{-1}$, respectively. The evaporation rate ranges from 0.2 to $0.4 \mathrm{~mm} \cdot \mathrm{d}^{-1}$ in North Africa and from 0.2 to $0.7 \mathrm{~mm} \cdot \mathrm{d}^{-1}$ in West Asia. The trend is weakly increasing in China-Mongolia. The evaporation contribution to precipitation decreases in North Africa and West Asia but increases in China-Mongolia, which differs from the results in Li [19] and Dominguez and Kumar [23]. The annual average precipitation recycling ratio ranges from 0.02 to $0.05,0.01$ to 0.02 and 0.01 to 0.05 in ChinaMongolia, North Africa and West Asia, respectively.

\section{Discussion and Conclusions}

This study investigated the evaporation characteristics in the arid regions of Asia and Africa using the precipitation recycling ratio to compare the key features of these arid regions. The main results are summarized as follows. 

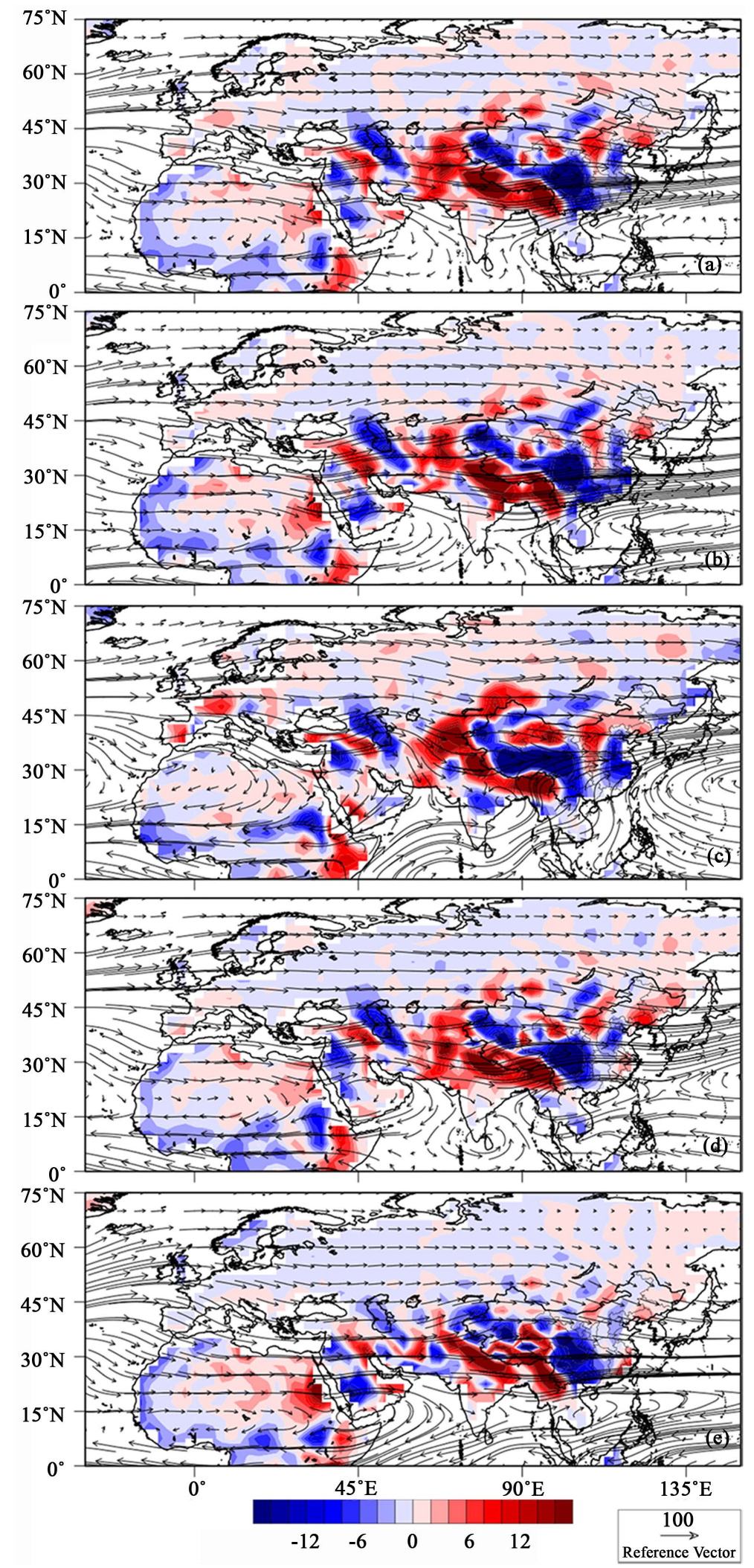

Figure 4. Average vertical integral water vapour transport flux (arrows, $\mathrm{kg} \mathrm{m}^{-1} \mathrm{~s}^{-1}$ ) and its divergence (shaded regions, $10^{-5} \mathrm{~kg} \cdot \mathrm{m}^{-2} \cdot \mathrm{s}^{-1}$ ). (a) Annual; (b) Spring; (c) Summer; (d) Autumn; (e) Winter. 


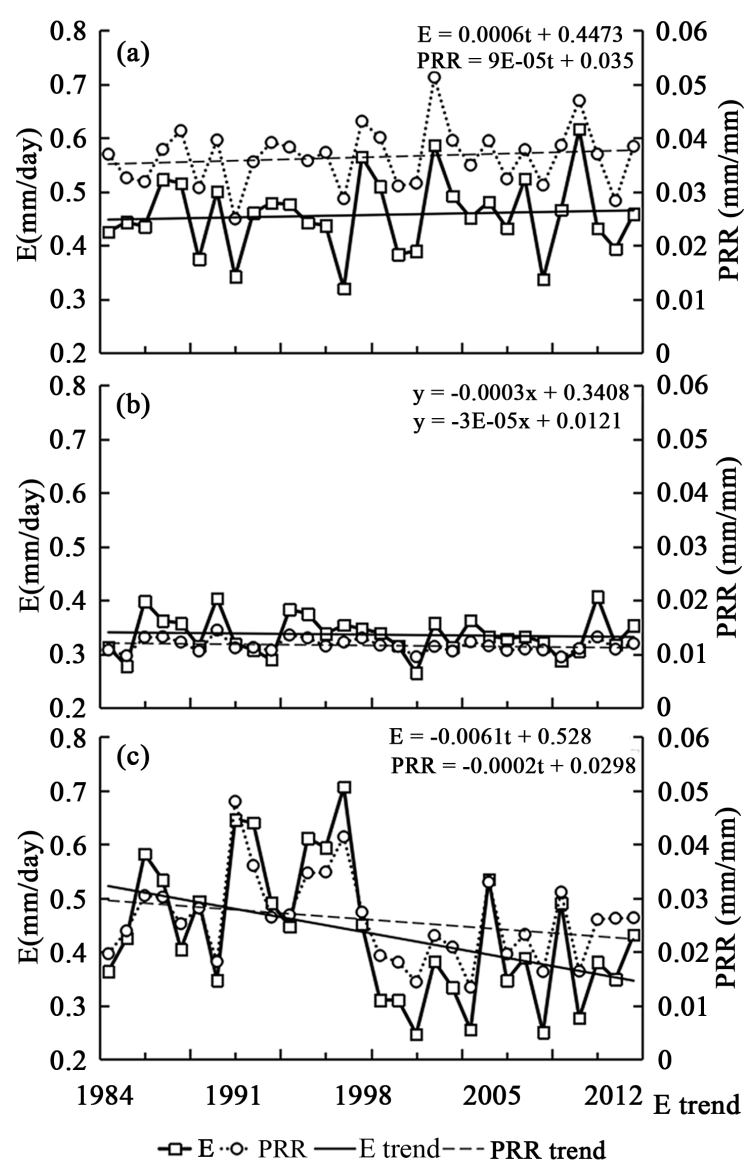

Figure 5. Annual evolution of evaporation (squares, $\mathrm{mm} \cdot \mathrm{d}^{-1}$ ) and precipitation recycling ration (circles, $\mathrm{mm} \cdot \mathrm{mm}^{-1}$ ) across (a) China-Mongolia; (b) North Africa and (c) West Asia from 1984 to 2013.

The spatial distribution of precipitation recycling is obvious, with an observed minimum in arid regions that increases significantly in the high-latitude arid regions. There are also significant seasonal changes. The precipitation recycling ratio in North Africa and China-Mongolia is higher in summer but lower in winter. However, precipitation recycling in North Africa is much stronger in winter and spring but weaker in summer.

Water vapour transport is the main precipitation source in arid regions. The main source of water vapour for North Africa is the Atlantic Ocean, which is to the west of this arid region. Water vapour is transported from the Red Sea and Mediterranean to the West Asia arid region. China-Mongolia is affected by terrestrial water vapour transmission from the west. Water vapour transportation over the arid regions is primarily manifested as water vapour convergence.

The precipitation recycling ratio is mainly dependent on evaporation. Precipitation recycling in arid regions is recalculated on the basis of evaporation via the water mass balance method. The results show that precipitation recycling is low in arid regions due to the low water supply via evaporation, and the contri- 
bution of local water vapour to total precipitation is small. The main water vapour source in arid regions is via external water vapour transportation. Increasing global temperatures have exhibited similar influences on the precipitation recycling ratio and evaporation trends. There has been a weak increase in China-Mongolia, whereas the precipitation recycling ratio has decreased in West Asia and North Africa.

The evaporation and precipitation recycling numerical model established in this paper is based on the water vapour balance equation, which has a strong mathematical basis. The reliability of the obtained results will be helpful in deepening our understanding of water recycling characteristics. The calculation method of evaporation on land in this paper can be widely used, but further experimental verification is needed on the ocean surface. In addition, the water balance in a short time scale is more complex, and more factors should be discussed in the next stage of research. It is also worth considering whether there are differences in precipitation recycling calculation using the DRM in different climate zones.

\section{Conflicts of Interest}

The author declares no conflicts of interest regarding the publication of this paper.

\section{References}

[1] Brubaker, K.L., Entekhabi, D. and Eagleson, P.S. (1993) Estimation of Continental Precipitation Recycling. Journal of Climate, 6, 1077-1089. https://doi.org/10.1175/1520-0442(1993)006<1077:EOCPR>2.0.CO;2

[2] Dominguez, F., Kumar, P., Liang, X.Z. and Ting, M. (2006) Impact of Atmospheric Moisture Storage on Precipitation Recycling .Journal of Climate, 19, 690-699. https://doi.org/10.1175/JCLI3691.1

[3] Burde, G.I. and Zangvil, A. (1999) The Estimation of Regional Precipitation Recycling. Part I: Review of Recycling Models. Journal of Climate, 14, 2497-2508.

[4] Wang, C. and Guo, Y. (2012) Precipitable Water Conversion Rates over the Qinghai-Xizang (Tibet) Plateau: Changing Characteristics with Global Warming. $\mathrm{Hy}$ drological Processes, 26, 1509-1516. https://doi.org/10.1002/hyp.8246

[5] Trenberth, K.E. (1998) Atmospheric Moisture Residence Times and Cycling: Implications for Rainfall Rates and Climate Change. Climatic Change, 39, 667-694. https://doi.org/10.1023/A:1005319109110

[6] Eltahir, E.A.B. and Bras, R.L. (1996) Precipitation Recycling. Reviews of Geophysics, 34, 367-378. https://doi.org/10.1029/96RG01927

[7] Eltahir, E.A.B. and Bras, R.L. (2010) Precipitation Recycling in the Amazon Basin. Quarterly Journal of the Royal Meteorological Society, 120, 861-880. https://doi.org/10.1002/qj.49712051806

[8] Zhang, C., Tang, Q. and Chen, D. (2016) Recent Changes in the Moisture Source of Precipitation over the Tibetan Plateau. Journal of Climate, 30.

[9] Burde, G.I. (2010) Bulk Recycling Models with Incomplete Vertical Mixing. Part I: Conceptual Framework and Models. Journal of Climate, 19, 1461-1472. 
[10] Schneider, U., Fuchs, T., Meyer-Christoffer, A. and Rudolf, B. (2005) Global Precipitation Analysis Products of the GPCC. Dtsch Wetterdienst.

[11] Fuchs, T., Schneider, U. and Rudolf, B. (2009) The Global Precipitation Climatology Centre (GPCC) - In Situ Observation Based Precipitation Climatology on Regional and Global Scale. EGU General Assembly Conference (Vol.11), EGU General Assembly Conference Abstracts.

[12] Raziei, T., Bordi, I., Pereira, L.S. and Sutera, A. (2010) Space-Time Variability of Hydrological Drought and Wetness in Iran Using NCEP/NCAR and GPCC Datasets. Hydrology \& Earth System Sciences, 14, 1919-1930. https://doi.org/10.5194/hess-14-1919-2010

[13] Raziei, T., Martins, D.S., Bordi, I., Santos, J.F., Portela, M.M., Pereira, L.S., et al. (2015) Spi Modes of Drought Spatial and Temporal Variability in Portugal: Comparing Observations, pt02 and GPCC Gridded Datasets. Water Resources Management, 29, 487-504. https://doi.org/10.1007/s11269-014-0690-3

[14] Qian, Z., Song, M., Tongwen, W.U. and Cai, Y. (2017) Review of Advances in World Dryland Climate Research (II): Main Investigation Progress. Plateau Meteorology.

[15] Thomas, D.S.G. (1997) Arid Zone Geomorphology Process. Form \& Change in Drylands.

[16] Liu, G.W. (1997) Atmosphere Process Hydrologic Cycle. Science Press.

[17] Li, R.L. (2017) The Changing Precipitation Conversion and Recycle and Changes over Northern Hemispheric Arid Regions under Global Warming. Doctoral Dissertation, Lanzhou University, Lanzhou.

[18] Guo, Y. and Wang, C. (2014) Trends in Precipitation Recycling over the Qinghai-Xizang Plateau in Last Decades. Journal of Hydrology, 517, 826-835. https://doi.org/10.1016/j.jhydrol.2014.06.006

[19] Li, R., Wang, C. and Wu, D. (2016) Changes in Precipitation Recycling over Arid Regions in the Northern Hemisphere. Theoretical \& Applied Climatology, 1-14.

[20] Ent, R.J.V.D. and Savenije, H.H.G. (2011) Length and Time Scales of Atmospheric Moisture Recycling. Atmospheric Chemistry and Physics, 11, 1853-1863.

https://doi.org/10.5194/acp-11-1853-2011

[21] Dirmeyer, P.A., Schlosser, C.A. and Brubaker, K.L. (2008) Precipitation, Recycling, and Land Memory: An Integrated Analysis. Journal of Hydrometeorology, 10, 278-288. https://doi.org/10.1175/2008JHM1016.1

[22] Guan, X., Huang, J. and Guo, R. (2017) Changes in Aridity in Response to the Global Warming Hiatus. Journal of Meteorological Research, 31, 117-125. https://doi.org/10.1007/s13351-017-6038-1

[23] Dominguez, F. and Kumar, P. (2008) Precipitation Recycling Variability and Ecoclimatological Stability-A Study Using Narr Data. Part I: Central U.S. Plains Ecoregion. Journal of Climate, 21, 5165-5186. https://doi.org/10.1175/2008JCLI1756.1 